\title{
Intervention programs for children whose parents have a mental illness: a review
}

Andrea E Reupert PhD, GradDipCounsPsych, Senior Lecturer

Rose Cuff DipOT

Statewide Project Coordinator ${ }^{2}$

Louisa Drost

MSc, Clinical

Psychologist/

Psychotherapist

Kim Foster

PhD,

Associate Professor of Mental Health Nursing ${ }^{4}$

Karin T M van Doesum

Senior Researcher/ Prevention Psychologist ${ }^{5}$

Floor van

Santvoort MSc

Researcher $^{5}$

1 Krongold Centre Faculty of Education.

Monash University,

Melbourne, VIC

2 Families where a Parent has a Mental Illness, The Bouverie Centre,

La Trobe University,

Melbourne, VIC

3 Indigo Community Mental Health Centre

GGZ Drenthe,

Assen, Netherlands.

4 Sydney Nursing School, University of Sydney

Sydney, NSW.

5 Radboud

University Nijmegen, Nijmegen, Netherlands.

andrea.reupert@ monash.edu

MJA Open 2012

1 Suppl 1: 18-22 doi: 10.5694/mjaoll.11l45
A n Australian epidemiological study found that $21 \%-23 \%$ of children have at least one parent who has a mental illness, ${ }^{1}$ with varying levels of risk exposure, depending on several child, parent, family and community variables. ${ }^{2}$ In recent years, there have been a number of programs that aim to promote the positive determinants of children's wellbeing and reduce the risk factors associated with living with parental mental illness. As these children are at higher risk of developing mental illnesses, suicide ideation and attempts, and functional impairment than their peers, ${ }^{2}$ it is essential that appropriate early intervention programs are developed. Scoping projects conducted in $1999^{3}$ and $2008^{4}$ found that peer-support programs were the main form of intervention offered in Australia. However, Fraser and colleagues ${ }^{5}$ found that the evaluation methodology employed by most programs, including such peer-support programs, was weak and thus their effectiveness was uncertain.

Our review aimed to identify the range of interventions that clinicians might employ, or refer to, when working with such children. Building on previous reviews, ${ }^{3-5}$ this article presents available interventions for children, highlighting evidence data when available. Given the different needs of very young children and older children, we focused on programs that target children aged 5-18 years (although some programs also include younger or older children).

\section{Methods}

Grey (unpublished) and black (published, peer-reviewed) literature was sourced from three fields. First, we examined a review of evaluated programs by Fraser and colleagues, ${ }^{5}$ as well as Australia-wide scoping projects conducted in $1999^{3}$ and $2008 .{ }^{4}$ Second, searches were conducted using PsycINFO and MEDLINE in June 2011, using key terms (list available from the authors on request) with no date limits, for papers published in English, Dutch or German. Finally, on the basis of these approaches, we identified various programs and circulated this list among our professional networks (carer and consumer groups, researchers and clinicians) to identify other programs and program types that we might have missed.

We included only those programs with a specific focus on children whose parents have a mental illness (excluding parental substance abuse). This meant that parenting programs for parents with a mental illness were excluded. Conversely, family programs were included if children were included in the intervention. Interventions targeting children with existing mental health problems were excluded. As the focus of our review was on identifying available programs, no restrictions were placed on study quality.

\begin{abstract}
Objective: To identify and describe intervention programs to improve outcomes for children whose parents have a mental illness.

Data sources: Grey and black literature was sourced from (i) three previous reviews/scoping studies, (ii) PsycINFO and MEDLINE searches of English, German and Dutch papers, and (iii) in consultation with researchers, clinicians, consumers and carers in the field.

Study selection: Only programs specifically targeting children whose parent/s have a mental illness. No restrictions were placed on study quality.

Data extraction: Program description, target group and evidence base.

Data synthesis: Programs from Australia, Europe and North America were found and collated into (i) family interventions, (ii) peer-support programs, (iii) online interventions and (iv) bibliotherapy. Some programs had been evaluated, with promising results. Others had minimal or no evaluation.

Conclusions: The core component across programs is the provision of psychosocial education to children about mental illness. More rigorous research is required to establish the conditions through which children's outcomes are enhanced.
\end{abstract}

Information extracted included program description, length, target group and available evidence base.

Programs from Australia, Europe and North America were found and collated into (i) family interventions, (ii) peer-support programs, (iii) online interventions, and (iv) bibliotherapy.

\section{Results}

\section{Family-intervention programs}

We identified seven family-intervention programs (Box 1$){ }^{6-13}$ Of these, six programs target families where a parent has depression and/or anxiety., ${ }^{7,810-13}$ The most prominent, Family Talk, targets families where a parent is diagnosed with a major depressive disorder or bipolar disorder, with children aged between 8 and 15 years who have never been treated for an affective disorder. ${ }^{10,11}$ Family Talk employs a cognitive psychoeducational approach of between six and 10 sessions, some of which are directed to parents, some to the children and some to the whole family. Another program, Family Options, ${ }^{9}$ employs a care-coordination model tailored for individual families where a parent has a serious mental illness; however, at this point, child outcomes are not available.

Overall, family programs focus on minimising family dysfunction and maximising children's support networks and competencies. Family programs can range from two to 20 sessions, and more research is required to determine 
Program: year, country

CAPS:

2009, USA 6

\section{Target population}

Parents with anxiety Six to eight weekly sessions and their children and three monthly booster aged $7-12$ years sessions; first two sessions with parents alone, others with the family

\begin{tabular}{|c|c|}
\hline $\begin{array}{l}\text { EFEKT-E: } \\
\text { 2011, Germany }\end{array}$ & $\begin{array}{l}\text { Parents with } \\
\text { depression and their children } \\
\text { children aged 4-7 } \\
\text { years }\end{array}$ \\
\hline
\end{tabular}
years
Family group cognitive behavioral preventive intervention: 2011, USA ${ }^{8}$

\author{
Parents with major \\ depressive disorder \\ and their children
} aged $9-15$ years
Intervention description

Children: anxiety management, cognitive restructuring, problem solving skills. Parents: anxiety management, contingency management, communication and problem-solving skills

Parents: education regarding parenting and impact of depression on children's development and parenting. Children:education regarding social problem-solving skills

Eight weekly and four monthly group sessions for family groups (four families per group)

Clinician-facilitated cognitive behavioural skills training to parents and children. Parents provided with parenting skill training and children with adaptive coping. Group meetings also with other families

Family Options: 2009, USA ${ }^{9}$

Parents with serious
mental illness and their children aged $1.5-16$ years

Family Talk: 2003, 2007, USA $^{10,11}$

Parents with affective disorder and their children aged $8-15$ years
Meetings at least weekly with Clinician facilitated a care the family and family members plan tailored to needs of over 12-18 months, depending family members on the need of the families (phone link also available) Lecture delivered over two meetings with group of parents; and six to 11 clinician- risk and resilience led weekly sessions with parents/children/family plus follow-up at 6-9 months

\section{Evaluation method and results}

Design: RCT comparing CAPS $(n=20)$ with waitlist control group $(n=20)$. Measures: ADIS Child Version, SCARED. Results: 30\% of waitlist children developed an anxiety disorder at 1-year follow-up compared with no children in CAPS group

Design: RCT of 375 families comparing usual care and intervention. Measures: group facilitators rated children's on-task and off-task behaviour during each session Mothers reported on children's social behaviour and skills. Results: children reported significantly less emotional disruption and hyperactivity

Design: RCT comparing family intervention $(n=56)$ and families receiving written information only $(n=55)$, at 18 and 24 months. Measures: CES-D; CBCL; K-SADSPL. Results: children in experimental group had significantly lower anxiety/depression levels and internalising symptoms at 18 months, and significantly lower externalising symptoms at 18 and 24 months

Design: qualitative (interviews) and quantitative (within-group), pre, 6, 12 and 18 months $(n=22)$. Results: no children's outcomes available yet

Design: RCT comparing lecture $(n=40)$ and clinician-led intervention $(n=69)$ pre, immediately post, $1,2.5$ and 4.5 years. Measures: K-SADS-PL, YSR questionnaire and semi-structured child interview. Results: at 4.5 years after clinician-led intervention: significantly more gains in children's understanding of parental disorder; children's functioning increased for both groups and internalising symptoms decreased

Keeping Families Strong: 2011, USA ${ }^{12}$

\section{Depressed mothers and their children aged $9-16$ years}

10 sessions including parent and child multifamily groups (no behavioural sessions more than four families in one group) and individual family group meetings

Let's Talk: 2010, Finland ${ }^{13}$
Parents with affective disorder and their children aged 8-16 years

\section{1-2 weekly sessions}

Clinician-facilitated psychoeducational sessions with parent/s
Design: within-group pre and post $(n=16)$. Measures: child coping strategies checklist; coping efficacy scale; BASC; LER. Results: decreased internalising symptoms, improved coping and decreased stressful family events

Design: RCT comparing Family Talk $(n=40)$ and Let's Talk $(n=44)$, at 4,10 and 18 months. Measures: SDQ; SCARED. Results: both interventions effective in decreasing children's emotional symptoms and anxiety, and in improving children's prosocial behaviour. Family Talk more effective on emotional symptoms immediately after intervention

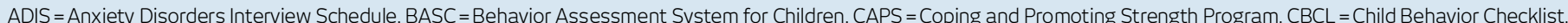

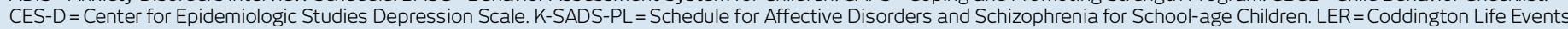

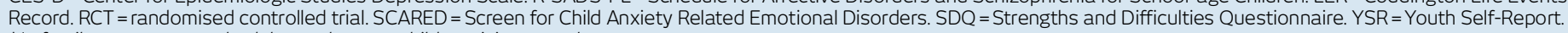
* In family programs, methodology relates to child participants only. 
2 Peer-support programs for children whose parents have a mental illness

Program:

year, country

Action for Young Carers: 2008 $\mathrm{UK}^{14}$

\section{Auryn groups:}

2001, Germany ${ }^{15}$

\section{CHAMPS:}

2009, Australia ${ }^{16}$

Target population

Intervention frequency

Not time limited

caring for their

parents with a mental illness

\section{7-16 year olds}

(split in separate

24-38 weekly sessions with children; home visit ( 1 week before start); four to six parent
sessions; one booster session Offered as either after-school weekly program or 3-4-day holiday program
Intervention description

Support and respite

Clinician-facilitated psychoeducation and support groups (children and parents)

Structured peer support, psychoeducational groups, family participation during program, activity based

\section{Evaluation method and results}

Design: qualitative interviews $(n=10)$. Results: participants valued project workers and group work

\section{None reported}

Design: within-group, pre, 4 weeks post $(n=69)$. Measures: Kids Connections, Kids Problems and Kids Coping scales; RSSE. Results: improvements in self-esteem, problem-focused coping and connections within family

Group cognitive

therapy

prevention: 2001, USA ${ }^{17}$

\section{3-18 year olds,} with a parent with depression, who reported subdiagnosticlevels of depressive symptoms but insufficient to meet full diagnosis of depression

Kids with

Confidence:

2009, Australia ${ }^{18}$

Kids in Contro 2006, Canada ${ }^{19}$

8-13 year old whose parent or
15 1-hour sessions for groups of six to 10 young adolescents

(n)

\section{2-18 year olds Monthly meetings} sibling has a mental illness

KOPING Program: 12-18 year olds 2008, 2009, Australia 20,21

Initial three group sessions; follow-up support
Teaching of cognitive restructuring techniques to identify and challenge irrational, unrealistic or overly negative thoughts. Three separate parent sessions conducted to inform parents about the program (but not to discuss parent's depression)

Semistructured activities that provide respite, education, support and fun
Design: RCT comparing usual care $(n=49)$ and intervention ( $n=45)$ pre, immediately post, 12 and 24 months. Measures: K-SADS-

PL to obtain diagnoses, CES-D, HAM-D, GAF. Results: Intervention group significantly less likely to report major depressive incidence

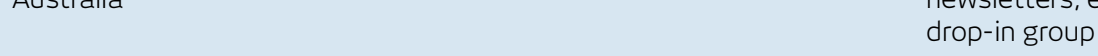

Learning about mental illness and practising coping and interpersonal skills; social support

\section{Peer-support groups.} Ongoing support, including newsletters, email contact,
Design: verbal feedback and program attendance. Results: regular attendance, reported improvements in self-esteem and confidence

Design: RCT (waitlist control), pre, post, 8 weeks ( $n=33$ ). Measures: CSEI, Kids Coping and Kids Knowledge scales. Results: higher levels of self-esteem and diminished use of maladaptive coping strategies

Design: RCT pre, post, 8 weeks $(n=44)$.

Measures: knowledge and awareness of parental mental illness measures; SC, RSQ, CDI, SWLS, SDQ, YCOPI. Results: increased mental health literacy, prosocial behaviour and life satisfaction. Decreased depression and emotional symptoms. No significant differences between groups

Peer-support groups (four to Design: Within-group, pre, post, 6 and 12 eight adolescents, peer leader, health professional); reference committee; recreational activities months $(n=64)$. Measures: MBCBS, PSSS, SPSI, SMFQ, plus self-developed scales. Results: significant reduction in depressive symptoms, risk of homelessness and experience of stigma. No differences reported over time in substance use, social support and problem solving

Play and talk groups:

Netherlands ${ }^{24}$

\section{8-12 year olds}

\section{Eight weekly sessions (child); one parent session; one booster session}

Positive Connections: 2003. USA ${ }^{25}$

\section{8-13 year olds}

Three phases of two consecutive 5-week groups; 6 months of mentoring
Clinician-facilitated psychoeducation and support groups. Activities include group conversations, role plays, games, homework assignments, leisure activities. One parent meeting

Clinician-facilitated psychoeducation and support groups; mentoring through Big Brothers/Big Sisters; graduation ceremony.
Design: RCT (waitlist control), pre, post, 3 months $(n=254)$. Measures: emotional and behavioural problems, negative cognitions, social support, competence, parent-child interaction. Results: not yet available

Design: Within-group, pre and post $(n=11)$. Measures: SEl, FAM, knowledge and coping skills measures. Results: significance not indicated; most measures showed improvement 


\begin{tabular}{|c|c|c|c|c|}
\hline $\begin{array}{l}\text { Program: } \\
\text { year, country }\end{array}$ & Target population & Intervention frequency & Intervention description & Evaluation method and results \\
\hline $\begin{array}{l}\text { SMILES: } \\
\text { 2004, Canada, } \\
\text { Australia26 }\end{array}$ & $\begin{array}{l}\text { 8-16 year olds } \\
\text { whose parent or } \\
\text { sibling had a mental } \\
\text { illness }\end{array}$ & 3-day consecutive program & $\begin{array}{l}\text { Peer-support groups; } \\
\text { activities include artwork, } \\
\text { games, singing, interactive } \\
\text { and relaxation exercises; } \\
\text { parent program }\end{array}$ & $\begin{array}{l}\text { Design: Within-group, pre and immediately } \\
\text { post }(n=25) \text {. Measures: knowledge and life } \\
\text { skills measures. Results: improvement in } \\
\text { knowledge of mental illness and self-rated } \\
\text { life skills }\end{array}$ \\
\hline $\begin{array}{l}\text { Youth and } \\
\text { Education } \\
\text { Support: } \\
\text { 2009, USA } 27\end{array}$ & 10-16 year olds & Six 2-hour sessions & $\begin{array}{l}\text { Mental health literacy, } \\
\text { adaptive coping strategies }\end{array}$ & $\begin{array}{l}\text { Design: Within-group, pre and post ( }(n=17) \text {. } \\
\text { Measures: A-COPE, KPIRT. Results: } \\
\text { knowledge significantly increased post- } \\
\text { intervention; no change in coping behaviour }\end{array}$ \\
\hline \multicolumn{5}{|c|}{$\begin{array}{l}\text { A-COPE = Adolescent Coping Orientation for Problem Experiences. CDI = Children's Depression Inventory. CES-D=Center for Epidemiologic Studies Depression Scale. } \\
\text { CHAMPS = Children and Mentally III Parents. CSEI = Coopersmith Self-Esteem Inventory. FAM = Family Assessment Measure. GAF = Global Assessment of Functioning Scale. } \\
\text { HAM-D = Hamilton Depression Rating Scale. KPIRT = Knowledge of Psychiatric Illness and Recovery Test. K-SADS-PL= Schedule for Affective Disorders and Schizophrenia for } \\
\text { School-age Children. MBCBS = Montgomery Borgatta Caregiver Burden Scale. PATS = Paying Attention to Self. PSSS = Multidimensional Scale of Perceived Social Support. } \\
\text { RCT = randomised controlled trial. RSQ = Responses to Stress Questionnaire (family stress version). RSSE = Rosenberg-Simmons Self-esteem Scale. SC = Social Connectedness Scale. } \\
\text { SDQ = Strengths and Difficulties Questionnaire. SEI = Self-esteem Index. SMFQ = Short Mood and Feelings Questionnaire. SMILES = Simplifying Mental Illness plus Life Enhancement } \\
\text { Skills. SPSI = Social Problem-solving Inventory. SWLS = Satisfaction with Life Scale. YCOPI= Young Caregiver of Parents Inventory. }\end{array}$} \\
\hline
\end{tabular}

whether intensity equates to effectiveness. While current evaluation data are mostly rigorous (employing a randomised controlled trial design), programs need to be developed and evaluated for families where a parent has disorders other than, or in addition to, depression. As shown in Box 1, programs indicate positive results in terms of children's symptoms.

\section{Peer-support programs}

We identified 12 peer-support programs, offered as school holiday programs, after-school programs, or camps (see Box 2). ${ }^{14-27}$ Peer-support programs target children aged 718 years, and aim to increase children's knowledge about mental illness, develop peer relationships and enhance children's adaptive coping skills. Programs commonly adopt a group, strengths-based, preventive approach. One program is facilitated by a peer leader who is also the child of a parent with a mental illness, thereby providing opportunities for the development of leadership skills. ${ }^{22,23}$

Potential risks associated with peer-support programs include exposing children to unsettling information about mental illness and limiting peer-support networks to those in the program. ${ }^{22}$ In one program, prosocial behaviour (measured by parents' scores on the Strengths and Difficulties Questionnaire) decreased as children began to ask more questions about mental illness. ${ }^{16}$ Five of the 12 programs have been, or are currently, offered in Australia. Although a number of peer-support programs have been evaluated, many have not used valid outcome measures and have not employed waitlist or control groups. Longitudinal data are often not available, so long-term outcomes remain unclear. Overall, it would be appear that the evidence base for peer-support programs is emerging.

\section{Online interventions}

We identified two online interventions targeting older children and young adults (12-25-year-olds) (Box 3). ${ }^{28-30}$ Websites provide easy access at all times of the day and the option of remaining anonymous when studying information and/or sharing experiences. Potentially, young people might misunderstand a message in the absence of non-verbal cues, and websites do not necessarily provide the opportunity for immediate clarification. Additionally, staff must be trained in computing skills. Future evaluation needs to focus specifically on child outcomes. We did not find any online interventions that were designed for Australian young people.

\section{Bibliotherapy}

Bibliotherapy presents children with literature involving characters who are in similar positions to themselves. This enables children to normalise their situation, gain insight into the problem-solving techniques of those characters, and apply this learning to their own lives. Tussing and Valentine $^{31}$ advocate employing bibliotherapy with children whose parents have a mental illness, in conjunction with discussions about the material with a trained professional. In Australia, the Children of Parents with a Mental Illness national initiative identifies various books, DVDs and consumer stories (many of which are Australian) that might be employed in this approach (http://www.copmi.net.au/jsp/resources/resource_ index.jsp). Bibliotherapy might consolidate other forms of psychoeducation, and could be useful for rural/remote populations and those on waiting lists. However, it requires a certain level of literacy and has the potential to be misinterpreted. There is no evidence for the efficacy of bibliotherapy in children affected by parental mental illness, although Marrs ${ }^{32}$ found that it was useful for adults, in conjunction with other forms of treatment.

\section{Summary}

The common component across programs is the provision of psychosocial education about mental illness to families and children. This suggests that it is important to provide age-appropriate information about mental illness to children whose parents have a mental illness, although further research is required to test this assumption. More evaluation is required to specifically examine the comparative efficacy of different approaches, to determine what interventions work, for whom, and how. With the exception of peer-support programs, most interventions are located in either Europe or North America. These interventions typically focus on children living with 


\section{Online interventions for children and young adults whose parents have a mental illness}

Program: year, country

Kopstoring: 2010,

Netherlands ${ }^{28}$

Target population

16-25-year-olds Intervention frequency

Eight weekly sessions

\section{Intervention description}

Theme-based online chat group meetings
Evaluation method and results

Design: multicentre randomised controlled trial with waitlist control. Measures: cost-effectiveness analysis, cost-utility analysis, Youth Self-report questionnaire. Results: not yet available

Survivalkid: 2011, $\quad$ 12-25-year-olds

Netherlands 29,30 12-25-year-olds

\section{Anonymous access at all times; weekly monitore}

Secluded virtual platform with personalised feedback, psychosocial education, message board, blog facility, monitored chat groups, and opportunities for private chats and email correspondence with a professional
Design: Usage statistics and satisfaction questionnaire. Results: increased access to information and support; peer support appreciated parental depression and/or anxiety. Although some programs have been evaluated in randomised controlled trials, further evaluation is required. Program evaluation needs to incorporate validated outcome measures and rigorous evaluation designs, compatible with the community settings in which many programs are delivered, and sensitive to the heterogeneous nature of the target group - children whose parents have depression and/or anxiety, as well as other disorders.

Competing interests: No relevant disclosures.

Provenance: Not commissioned; externally peer reviewed.

Received 11 Sep 2011, accepted 19 Mar 2012.

1 Maybery DJ, Reupert AE, Patrick K, et al. Prevalence of parental mental illness in Australian families. The Psychiatrist 2009; 33: 22-26. doi: 10.1192/pb.bp.107.018861.

2 Hosman $\mathrm{CMH}$, van Doesum KTM, van Santvoort F. Prevention of emotional problems and psychiatric risks in children of parents with a mental illness in the Netherlands: I. The scientific basis to a comprehensive approach. Adv Ment Health [internet] 2009; 8: 250-263.

3 Australian Infant, Child, Adolescent and Family Mental Health Association. Children of parents affected by a mental illness - Scoping project. Stepney, SA: AICAFMHA, 2001. http://www.aicafmha.net.au/ projects/scoping/file/intro.htm (accessed Mar 2012).

4 Reupert A, Goodyear M, Eddy K, et al. Australian programs and workforce initiatives for children and their families where a parent has a mental illness. Adv Ment Health [internet] 2009; 8: 277-285. doi: 10.5172/jamh.8.3.277

5 Fraser C, James EL, Anderson K, et al. Intervention programs for children of parents with a mental illness: a critical review. Int J Ment Health Promotion 2006; 8: 9-20.

6 Ginsburg GS. The Child Anxiety Prevention Study: intervention model and primary outcomes. J Consult Clin Psychol 2009; 77: 580-587.

7 Bühler A, Kötter C, Jaursch S, Lösel F. Prevention of familial transmission of depression: EFEKT-E, a selective program for emotionally burdened families. J Public Health 2011; 19: 321-327. doi: 10.1007/s10389-011-0423-5.

8 Compas BE, Forehand R, Thigpen JC, et al. Family group cognitivebehavioral preventive intervention for families of depressed parents: 18- and 24-month outcomes. J Consult Clin Psychol 2011; 79: 488-499.

9 Nicholson J, Albert K, Gershenson B, et al. Family options for parents with mental illnesses: a developmental, mixed methods pilot study. Psychiatr Rehabil J 2009; 33: 106-114.

10 Beardslee WR, Gladstone TR, Wright EJ, Cooper AB. A family-based approach to the prevention of depressive symptoms in children at risk: evidence of parental and child change. Pediatrics 2003; 112: el19-el31.

11 Beardslee WR, Wright EJ, Gladstone TR, Forbes P. Long-term effects from a randomized trial of two public health preventive interventions for parental depression. J Fam Psychol 2007; 21: 703-713.

12 Valdez CR, Mills CL, Barrueco S, et al. A pilot study of a family-focused intervention for children and families affected by maternal depression. J Fam Ther 2011; 33: 3-19. doi: 10.1111/j.1467-6427.2010.00529.x.

13 Solantaus T, Paavonen EJ, Toikka S, Punamäki RL. Preventive interventions in families with parental depression: children's psychosocial symptoms and prosocial behaviour. Eur Child Adolesc Psychiatry 2010; 19: 883-892.
14 Grant G, Repper J, Nolan M. Young people supporting parents with mental health problems: experiences of assessment and support. Health Soc Care Community 2008; 16: 271-281.

15 Dierks H. [Prevention groups for school-aged children of mentally ill parents ("Auryn Groups")] [German]. Prax Kinderpsychol Kinderpsychiatr 2001; 50: 560-568.

16 Goodyear M, Cuff R, Maybery D, Reupert A. CHAMPS: A peer support program for children of parents with a mental illness. Adv Ment Health [internet] 2009; 8: 296-304. doi: 10.5172/jamh.8.3.296.

17 Clarke GN, Hornbrook M, Lynch F, et al. A randomized trial of a group cognitive intervention for preventing depression in adolescent offspring of depressed parents. Arch Gen Psychiatry 2001; 58: 1127-1134.

18 Hayman F. Kids with confidence: a program for adolescents living in families affected by mental illness. Aust J Rural Health 2009; 17: 268-272.

19 Richter GA. Fostering resilience: evaluating the effectiveness of Kids in Control [MA thesis]. Langley, BC: Trinity Western University, 2006.

20 Fraser E, Pakenham Kl. Evaluation of a resilience-based intervention for children of parents with mental illness. Aust N Z J Psychiatry 2008; 42: 1041-1050.

21 Morson S, Best D, de Bondt N, et al. The Koping Program: a decade's commitment to enhancing service capacity for children of parents with a mental illness. Adv Ment Health 2009; 8: 296-295. doi: 10.5172/ jamh.8.3.286

22 Hargreaves J, Bond L, O'Brien M, et al. The PATS peer support program. Prevention/early intervention for adolescents who have a parent with mental illness. Youth Studies Australia 2008; 27: 43-51.

23 Hargreaves J, O'Brien M, Bond L, et al. Paying Attention to Self (PATS): an evaluation of the PATS program for young people who have a parent with a mental illness. Melbourne: Centre for Adolescent Health 2005. http://www.rch.org.au/emplibrary/pats/PATS_FinalEvaluation Report_Dec2005.pdf (accessed Aug 2007).

24 van Santvoort F. Hosman CMH, van Doesum KTM, et al. Effectiveness of preventive support groups for children (8-12) of mentally ill or addicted parents. In prep.

25 Orel NA, Groves PA, Shannon L. Positive Connections: a programme for children who have a parent with a mental illness. Child Fam Soc Work 2003; 8: 113-122. doi: 10.1046/j.1365-2206.2003.00273.x.

26 Pitman E, Matthey S. The SMILES program: a group program for children with mentally ill parents or siblings. Am J Orthopsychiatry 2004; 74: 383-388.

27 Riebschleger J, Tableman B, Rudder D, et al. Early outcomes of a pilot psychoeducation group intervention for children of a parent with a psychiatric illness. Psychiatr Rehabil J 2009; 33: 133-141.

28 Woolderink M, Smit F, van der Zanden R, et al. Design of an internetbased health economic evaluation of a preventive group-intervention for children of parents with mental illness or substance use disorders. BMC Public Health 2010; 10: 470.

29 Drost LM, Cuijpers P. Schippers GM. Developing an interactive website for adolescents with a mentally ill family member. Clin Child Psychol Psychiatry 2011; 16: 351-364.

30 Drost LM, Sytema S, Schippers GM. Internet support for adolescents with a mentally ill family member. Psychiatr Serv 2011; 62: 322.

31 Tussing HL, Valentine DP. Helping adolescents cope with the mental illness of a parent through bibliotherapy. Child Adolesc Soc Work J 2001; 18: 455-469.

32 Marrs RW. A meta-analysis of bibliotherapy studies. Am J Community Psychol 1995; 23: 843-870. 
